\title{
Antioxidant and Quorum Quenching Activity against Pseudomonas aeruginosa SU-18 of some Edible Fruit Juices
}

\author{
Jenifer Selvarani A. ${ }^{1}{ }^{1}$, Nishanthini P. ${ }^{1}$, Raji P. ${ }^{1}$, Sree Samanvitha K. (D) ${ }^{2}$, Ponnaiah \\ Paulraj ${ }^{3}$, Iyappan $\mathrm{P}^{3}$, Chandramohan $\mathrm{M.}^{3}$, and Antony V. Samrot ${ }^{3 *}$
}

${ }^{1}$ Department of Biotechnology, School of Bio and Chemical Engineering, Sathyabama Institute of Science and Technology, Sholinganallur, Rajiv Gandhi Salai, Chennai, Tamil Nadu - 600 119, India. ${ }^{2}$ Department of Biotechnology, Shanmugha Arts, Science, Technology \& Research Academy, Thanjavur, India. ${ }^{3}$ Department of Biomedical Sciences, Faculty of Medicine and Biomedical Sciences, MAHSA University, Jalan SP2, Bandar Saujana Putra, 42610, Jenjarom, Selangor, Malaysia.

\begin{abstract}
Besides being an essential source of nutrients, the bioactive components of some fruits also help in enhancing the physiological functions by expressing its therapeutic action, acting as radical scavenger, improving digestion and healing. Here, seven edible fruits juices of Punica granatum, Citrus reticulata, Anana scomosus, Ficus carica, Vitis vinifera, Vitis amurensis and Carica papaya were utilized against biofilm forming Gram negative bacteria, Pseudomonas aeruginosa to evaluate its effect on Quorum sensing. On proving its antibacterial activity and anti-swarming motility in our earlier report, this work is extended to determine the biofilm inhibitory action of these fruit juices due to the impact on AHL (Acyl Homoserine lactone), the signaling molecule responsible for developing cell-cell communication and also on AHL mediated metabolites production. The fruit juices were evaluated for their Antioxidant activity on subjecting to TLC bioautography, DPPH and FRAP assay. AHL, Pyocyanin and Rhamnolipid were extracted from fruit juices treated Pseudomonas aeruginosa and the influence of fruit juice was identified by FT-IR and LC-MS analysis. However, AHL production was not stopped by fruit juice molecules but showed least production level in Punica granatum treated P.aeruginosa. Whereas the production of pyocyanin pigment was disturbed in Punica granatum, Citrus reticulata, Vitis amurensis and Vitis vinifera treated culture. The production of a biosurfactant called Rhamnolipid (Rha 10) was a failure in Citrus reticulata, Vitis amurensis, Vitis vinifera and Ficus carica treated P.aeruginosa. Thus the organism was restrained by the fruit juice molecules from expressing its virulence factors in spite of having no impact on AHL synthesis.
\end{abstract}

Keywords: Quorum sensing, biofilm, AHL, virulence factors, Pseudomonas aeruginosa.

*Correspondence: antonysamrot@gmail.com

(Received: 28 August 2019; accepted: 21 September 2019)

Citation: Jenifer Selvarani A., Nishanthini P., Raji P., Sree Samanvitha K., Ponnaiah Paulraj, Iyappan P., Chandramohan M., and Antony V. Samrot, Antioxidant and Quorum Quenching Activity against Pseudomonas aeruginosa SU-18 of some Edible Fruit Juices, J Pure Appl Microbiol., 2019; 13(3): 1863-1876. https://doi.org/10.22207/JPAM.13.3.64

(c) The Author(s) 2019. Open Access. This article is distributed under the terms of the Creative Commons Attribution 4.0 International License which permits unrestricted use, sharing, distribution, and reproduction in any medium, provided you give appropriate credit to the original author(s) and the source, provide a link to the Creative Commons license, and indicate if changes were made. 


\section{INTRODUCTION}

Pseudomonas aeruginosa exhibits its pathogenicity by the formation of a biofilm with the association of different communities on the host surface. Biofilm formation is an ubiquitous behavior of Pseudomonas aeruginosa where the free-floating planktonic cells gets attached to the biotic or abiotic substratum with the help of extracellular appendages via flagella, type IV pili and cup fimbriae for adhesion and multiplies into a microcolony within a slimy secretion called as Extracellular matrix (ECM) ${ }^{1}$. The chronicity of disease by $P$. aeruginosa is fully accomplished on biofilm formation which brings out characteristic phenotypic and genotypic traits in the microbial community such as resistance to environmental challenges, antibiotic infiltration, and against the host immune system².

The biofilm formation is facilitated by an intercellular signaling mechanism called quorum sensing (QS), carried out with the reception of signaling molecule called Acyl homoserine Lactone $(\mathrm{AHL})^{3}$. QS is responsible for regulation of several bacterial behaviors like virulence factor expression (elastase, rhamnolipids, phospholipase C, lecithinase, hemolysins), pigment production and motility ${ }^{4}$. The signaling mechanism is carried out by two systems, las and $r h l^{5}$. The las system comprises of signal synthase Lasl, to produces N-3oxo-dodecanoyl-homoserine lactone (30C12-HSL) and LasR as the signal receptor to bind as cognate signal and thereby activates transcription of target genes $^{6}$. The second QS system, the $r h /$ generates $\mathrm{N}$-butanoyl-homoserine lactone (C4-HSL) through the signal, synthase Rhll and the signal receptor $\mathrm{RhIR}$, which stimulate the gene expression on complexing with $\mathrm{C}-\mathrm{HSL}^{7}$. With multiple drugs on trial and development, researchers have explicated and highlighted many plant-based products to possess anti-biofilm property by inhibiting the QS, capping the signaling molecules, suppression of ECM secretion, physiological gene mutation of virulence factors and sensitivity in adhesion onto surfaces ${ }^{8}$.

The prevalence of Pseudomonas aeruginosa as biofilm is reported to be controlled by various dietary foods and food products, creating a new scope for effective drug formulation. Being a natural source of drugs, they could possibly overrule synthetic drugs and their harmful side effects. The in-vivo experimentation using garlic extracts on mouse UTI model show casted the limiting production of virulence factor and QS signal molecules and a potent anti-QS agent namely $\mathrm{N}$-(heptylsulfanylacetyl)-L-homoserine lactone was identified from garlic on further screenings ${ }^{9}$. Chang et al. ${ }^{10}$ confirmed that tannic acid, salicylic acid and trans-cinnamaldehyde represented as strong AHL inhibitor by disrupting $\mathrm{Rhl}$ QS system mediated pyocyanin production in $P$. aeruginos $a^{10}$. He also suggested that transcinnamaldehyde caused structural modifications to Lasl and Esal by targeting AHL synthase thus acting as non-antibiotic quorum sensing inhibitors. Chong et al. ${ }^{11}$ reported the anti-QS effect of four Chinese medicinal plants, Angelica dahurica, Rhizoma cibotii, Poria cum, Radix pini and Schizonepeta tenuifolia, on Pseudomonas aeruginosa PAO1 by affecting their swarming motility and pyocyanin production ${ }^{11}$. The extracts from an edible seed commonly called fenugreek (Trigonella foenum-graecum L.) was found to reduce the $A H L$ production and thereby hinder the biofilm formation by the down regulation of lasB gene in Pseudomonas aeruginosa $\mathrm{PAO}^{12}$. Likewise, this work deals with concentrated fruit juices of edible choices to identify their anti-QS property.

Upon stating the antibacterial and biofilm inhibition property of the fruit juices from Punica granatum (Pomegranate), Carica papaya (Papaya), Citrus reticulata (Orange), Ananas comosus (Pineapple), Vitis vinifera (Green grape), Ficus carica (Fig) and Vitis amurensis (Black grape) on P.aeruginosa SU18 in our earlier report, the study is pursued to check its effect on the secretory molecules of the organism such as AHL, pyocyanin and Rhamnolipid. These extracted components were subjected to FT-IR and LC-MS to analyse the effect on the quality and potency of these secretory molecules.

\section{MATERIALS AND METHODS \\ Preparation of Fruit Juices}

The concentrated fruit juices of Punica granatum, Citrus reticulata, Vitis amurensis, Vitis vinifera, Carica papaya, Ananas comosus and Ficus carica were prepared following the prior report ${ }^{13}$. 


\section{Antioxidant Activity by Assays Qualitative Antioxidant Activity on Thin Layer Chromatography \\ DPPH spray technique was followed as} a preliminary screening for antioxidant activity. The TLC plates were developed for the fruit juices under the solvent system as mentioned previously (Samrot et al., 2018). The developed plates were sprayed with DPPH $(0.04 \% \mathrm{w} / \mathrm{v}$ in $95 \%$ methanol) to qualitatively detect the antioxidant property possessed by the components of the fruit juices ${ }^{14}$. Quantitative Antioxidant Assays

\section{DPPH Radical Scavenging Assay}

The free radical scavenging activity for the concentrated fruit juices were experimented by DPPH (2,2-diphenyl-1-picryl-hydrazyl-hydrate) assay following Rahman et al. ${ }^{15}$ against ascorbic acid as the standard. Briefly, different volumes of concentrated fruit juices such as $50 \mu \mathrm{l}, 100$ $\mu \mathrm{l}, 150 \mu \mathrm{l}, 200 \mu \mathrm{l}$ and $250 \mu \mathrm{l}$ were made up to $1 \mathrm{ml}$ with methanol and added with $1 \mathrm{ml}$ of DPPH solution $(0.004 \% \mathrm{w} / \mathrm{v}$ in methanol). The reaction mixture was incubated in dark for 30 min at room temperature. The absorbance of the reaction mixture was read at $517 \mathrm{~nm}$ using spectrophotometer. $1 \mathrm{ml}$ methanol in $1 \mathrm{ml}$ of DPPH solution was used as blank material. The antiradical activity of the fruit juices were calculated in \% from the following formula

$$
\begin{gathered}
\text { \% Radical Scavenging Activity }= \\
{\left[\left(\mathrm{Ab}_{\text {control }}-\mathrm{Ab}_{\text {sample }}\right) / A b_{\text {control }}\right] \times 100}
\end{gathered}
$$

\section{Ferric Reducing Antioxidant Power (FRAP) Assay}

The reducing nature of the fruit juice was determined by FRAP assay ${ }^{16,17}$. Having ascorbic acid as standard, the concentrated fresh fruit juices were used in different volumes ranging $50 \mu \mathrm{l}, 100$ $\mu \mathrm{l}, 150 \mu \mathrm{l}, 200 \mu \mathrm{l}, 250 \mu \mathrm{l}$ and made up to $1 \mathrm{ml}$ with methanol. To this, $2.5 \mathrm{ml}$ of phosphate buffer (0.2 $\mathrm{M}, \mathrm{pH} 6.6$ ) and $2.5 \mathrm{ml}$ of $1 \%$ potassium ferricyanide was added. The mixture was incubated at $50^{\circ} \mathrm{C}$ for $20 \mathrm{~min}$. This mixture was treated with $2.5 \mathrm{ml}$ of 10 $\%$ trichloroacetic acid to stop the reaction, which was then centrifuged at $3000 \mathrm{rpm}$ for $10 \mathrm{~min}$. The upper layer of solution $(2.5 \mathrm{ml})$ was mixed with distilled water $(2.5 \mathrm{ml})$ followed by addition of 0.5 $\mathrm{ml}$ of $0.1 \% \mathrm{FeCl}_{3}$. The absorbance for the above reaction mixture was measured at $700 \mathrm{~nm}$ against a blank.

\section{Culturing Pseudomonas aeruginosa with Concentrated Fresh Fruit Juices}

The uropathogen used in our previous report, Pseudomonas aeruginosa SU18 with the accession number - MH134589 was maintained and utilized for performing the AHL impact study. Sterile nutrient broth was added with $5 \%$ freshly prepared concentrated fruit juices of Punica granatum, Citrus reticulata, Ficus carica, Vitis vinifera, Vitis amurensis, Carica papaya and Ananas comosus. Each of the fruit juice sample in nutrient broth were seeded with $12 \mathrm{ml}$ of overnight old culture of Pseudomonas aeruginosa aseptically and incubated at $37^{\circ} \mathrm{C}$ for $48 \mathrm{~h}$. As already discussed, AHL plays major role in biofilm formation as well as responsible for the virulence factors like pyocyanin and rhamnolipid. After incubation period, the culture was subjected for isolation and purification of AHL, pyocyanin and rhamnolipid to study the impact caused by the fruit extracts to $A H L$ as well as on $A H L$ induced pyocyanin and rhamnolipid.

Extraction of Acyl Homoserine Lactone (AHL)

After $48 \mathrm{~h}$ incubation as stated before, the cell free broth was added to twice the volume of ethyl acetate acidified by $0.5 \%$ acetic acid for three times. The solvent phase was separated using separating funnel and was evaporated to dryness. Thus obtained evaporated cum residua were brought into suspension by adding $1 \mathrm{ml}$ of Acetonitrile (ACN). Thus extracted samples primarily consist of $\mathrm{AHL}$ and were stored in deep freeze at $-20^{\circ} \mathrm{C}^{18}$.

\section{Extraction of Pyocyanin}

Nutrient broth with fruit juice and organism was centrifuged at $10,000 \mathrm{rpm}$. The cell free broth was further processed in accordance with Essar et al., ${ }^{19} .12 \mathrm{ml}$ of chloroform was added to $20 \mathrm{ml}$ of supernatant and vortexed. The sample was spun at $10,000 \mathrm{rpm}$ for $10 \mathrm{~min}$ resulting in two phases in which chloroform along with pyocyanin sinks to the bottom. Solvent phase was mixed with $0.2 \mathrm{~N} \mathrm{HCL}$ till the color changed from blue-green to pink. The solvent phase was centrifuged again at 10,000rpm for $2 \mathrm{~min}$. The resulting pink layer consists of the Pyocyanin pigment.

\section{Extraction of Rhamnolipid}

Minimal Medium with following composition g/l: $\mathrm{NH}_{4} \mathrm{NO}_{3}(2 \mathrm{~g}), \mathrm{KH}_{2} \mathrm{PO}_{4}(3 \mathrm{~g})$, 
$\mathrm{Na}_{2} \mathrm{HPO}_{4}(6 \mathrm{~g}), \mathrm{NaCl}(5 \mathrm{~g}), \mathrm{MgSO}_{4}(1 \mathrm{~g})$ and $2 \%$ of olive oil as carbon source was prepared. The $\mathrm{pH}$ of the media was adjusted to 7.0 and sterilized at $121^{\circ} \mathrm{C}$ for $15 \mathrm{~min} .5 \%$ concentrated fresh fruit juice was added to $100 \mathrm{ml}$ of sterile minimal media followed by addition of $12 \mathrm{ml}$ of $24 \mathrm{~h}$ nutrient broth culture of Pseudomonas aeruginosa. After incubation period of $24 \mathrm{~h}$, the media was centrifuged at $9000 \mathrm{rpm}$ for $15 \mathrm{~min}$ to remove the bacterial cells. The $\mathrm{pH}$ of the supernatant was adjusted to 2.0 by $1 \mathrm{~N}$ Hydrocholoric acid (HCL) to precipitate the Rhamnolipid ${ }^{20}$. The acidified supernatant was centrifuged at $9000 \mathrm{rpm}$ for 20 $\mathrm{min}$ to pelletize the precipitate. The harvested precipitate was extracted three times with ethyl acetate at room temperature. The ethyl acetate layer was separated using separating funnel ${ }^{21}$. Rhamnolipid was obtained as residue by letting the ethyl acetate evaporate in Fume-hood.

Characterization of Quorum Sensing Molecules Fourier-Transform Infrared Spectroscopy (FT-IR)

The functional groups and chemical bonds present in the extracted samples can be assessed by performing FTIR spectroscopy, which helps in structural elucidation and identification of the sample. The IR spectra were recorded on a Shimadzu IR affinity-1 FTIR- spectrometer
(Japan) in the $4000-500 \mathrm{~cm}^{-1}$ spectral regions at a resolution of $1 \mathrm{~cm}^{-1}$ with \% Transmittance as $y$-axis. Liquid Chromatography Mass spectrometry (LCMS)

LC-MS analysis for the extracted AHL, Pyocyanin and Rhamnolipid were performed by using Agilent 6400 Series Triple Quadrapole. The samples were eluted with an isocratic mobile phase of Acetonitrile: $5 \mathrm{mM}$ Ammonium formate (70:30).

\section{RESULTS AND DISCUSSIONS}

\section{Antioxidant Activity Assays}

TLC Bioautography for Antioxidant Activity

As an evidence for antioxidant activity, the discoloration of sprayed DPPH from purple to yellow with florescence was observed in all developed TLC plates ${ }^{22}$. Thus, confirming the presence of DPPH reactive molecules in the concentrated fresh fruit juices of Punica granatum, Citrus reticulata, Vitis amurensis, Carica papaya, Vitis vinifera, Ananas comosus and Ficus carica as visualized in Fig. 1. Citrus reticulata with $\mathrm{Rf}$ at 0.20 and 0.76 , Punica granatum with 0.43 , Vitis vinifera at 0.08 , Ananas comosus at 0.45 and Ficus carica at 0.33 showed antioxidant activity.
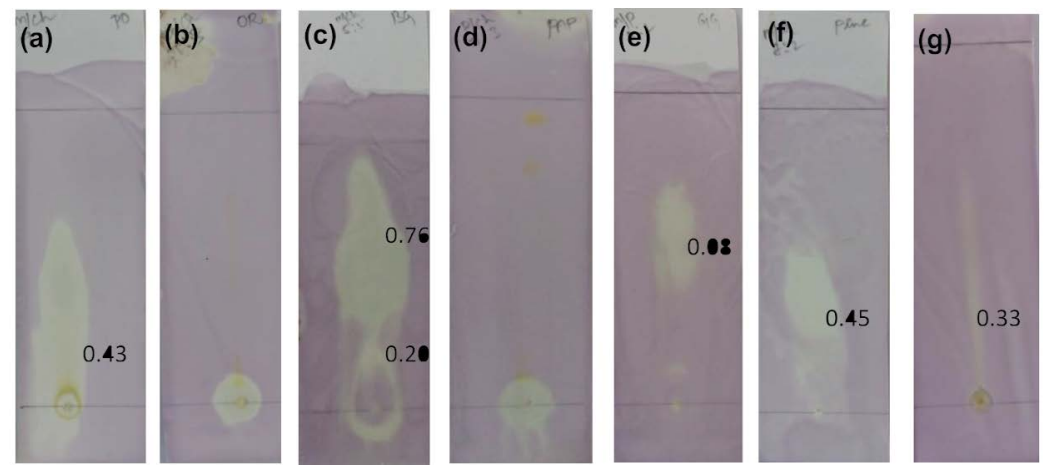

Fig. 1. TLC bioautography for antioxidant activity

(a) Punica granatum, (b) Citrus reticulata, (c) Vitis amurensis, (d) Carica papaya, (e) Vitis vinifera,

(f) Ananas comosus, (g) Ficus carica

\section{DPPH Assay}

DPPH assay was performed by taking different volumes of each concentrated fresh fruit juices where ascorbic acid was used as standard and the absorbance was measured at $517 \mathrm{~nm}$. Ficus carica was found to show high antioxidant activity followed up by Carica papaya, Vitis vinifera, Citrus reticulata, Punica granatum, Vitis amurensis, Ananas comosus. The anti-radical activity augmented with increase in volumes of fresh fruit juices used. The graph was plotted with volumes of fresh fruit juices on $X$ axis and their \% radical scavenged on $Y$ axis (Fig. 2). Carica papaya and Ficus carica showed $50 \%$ 


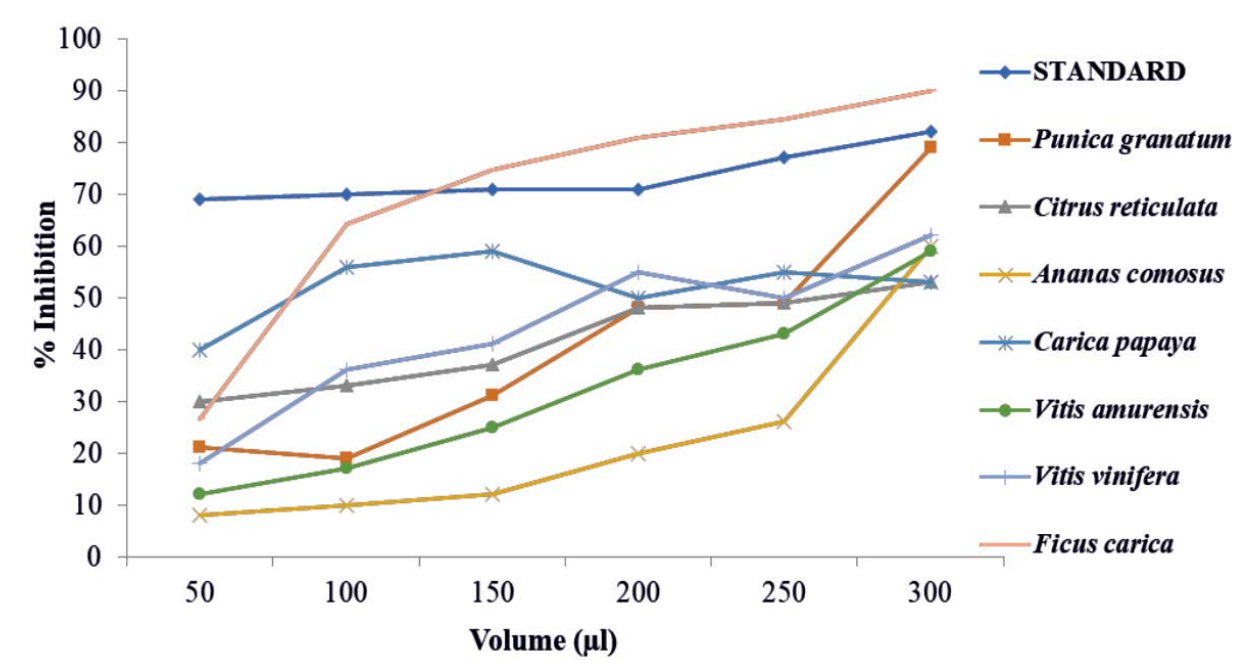

Fig. 2. Antioxidant Activity by DPPH assay

of anti-radical activity at the minimum volume between $50 \mu \mathrm{l}-100 \mu \mathrm{l}$. Followed by Vitis vinifera at $180 \mu \mathrm{l}-200 \mu \mathrm{l}$ to scavenge $50 \%$ of DPPH radical. $200 \mu \mathrm{l}$ of concentrated Punica granatum exhibited $50 \%$ radical scavenging action, at 250 $\mu \mathrm{l}$ for Citrus reticulata and fruits juices ofAnanas comosus and Vitis amurensis showed $50 \%$ of its radical scavenged at a volume of $250 \mu \mathrm{l}-300 \mu \mathrm{l}$. Basiri, (2013) reported the antioxidant property of pomegranate seed extracts ${ }^{23}$. The phenolic extract of Ananas comosus was described to have antioxidant activity by Haripyaree et $a .^{24}$. Yi et al.(2008) stated the radical scavenging profile of pericarp extracts from Citrus reticulata ${ }^{25}$. Freezedried ripe Carica papaya in aqueous extract also showed radical scavenging action up to $93 \%$ as quoted by Annegowda et al. ${ }^{26}$. Junior et al. ${ }^{27}$ stated that citrus possess antioxidant nature due to presence of major constituent of oil called limonene.

\section{FRAP Assay}

FRAP test was performed for all concentrated fruit juices against ascorbic acid as standard. The absorbance was recorded at 700nm. A graph was plotted with volume of concentrated fruit juices on $X$ axis and absorbance on $Y$ axis (Fig. 3). The absorbance increased for increase in volume of fruit juices added. From relating the absorbance data, the order of antioxidant expression by the fruits are as follows Ficus
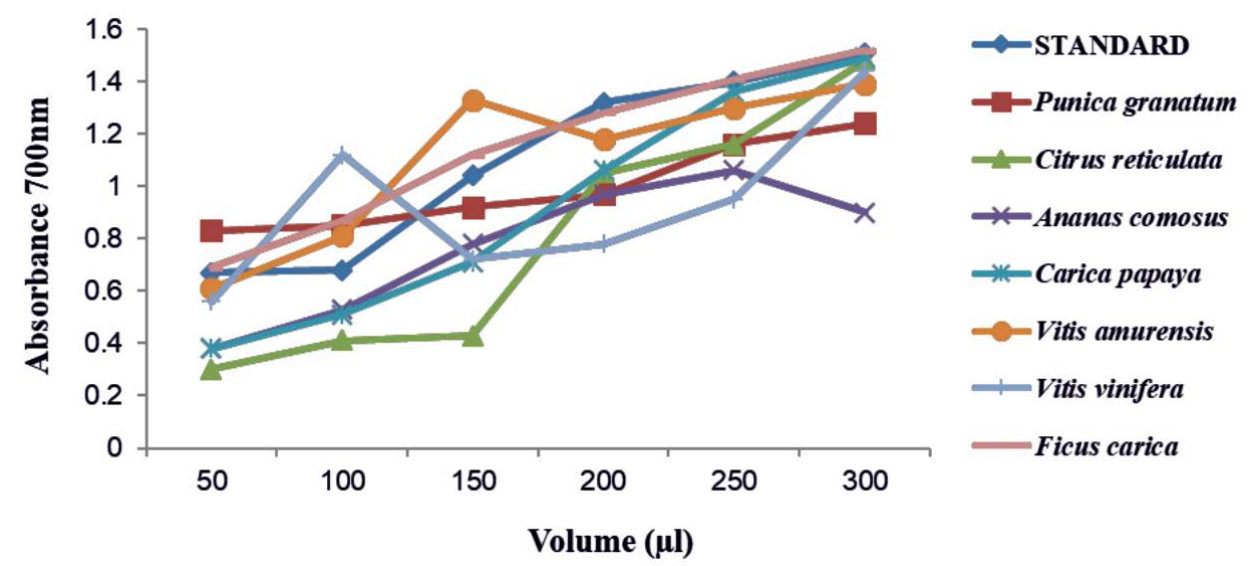

Fig. 3. Antioxidant activity by FRAP assay 
carica, Vitis amurensis, Punica granatum, Carica papaya, Ananas comosus, Vitis vinifera and Citrus reticulata. Above all, the juice of Ficus carica was found to show high antioxidant activity. With increase in concentration of fresh fruit juices, antioxidant activity progressively increased for Punica granatum and Carica papaya. The graph represents some irregular rising pattern of ferric reducing power with increase in volume for Citrus reticulata, Ananas comosus, Vitis vinifera, Vitis amurensis. Misharina and Samusenko 2008 found that antioxidant power (FRAP) possessed by essential oils from lemon, grapefruit, and their mixtures ${ }^{28}$. The study of Hassimoto et $a l^{29}$ observed that the pineapple varieties have antioxidant nature and also Kongsuwan et al. ${ }^{30}$ stated that the level of contents of vitamin C, phenolic compounds, carotene do not influence antioxidant activity. The hydroalcoholic extracts of Ficus carica leaves were reported to show antioxidant and anti-inflammatory property by Ali et al. $(2012)^{31}$.

\section{FRUIT JUICES AS QUORUM QUENCHERS}

Impact on Acyl Homoserine Lactone

The FT-IR spectrum of AHL is shown in (Fig. 4). The IR spectrum of AHL extracted from the different concentrated fresh fruit juice treated P.aeruginosa showed transmittance trough at $918 \mathrm{~cm}^{-1}$ corresponding to aromatic groups, 1375 $\mathrm{cm}^{-1}$ which represent the involvement of $\mathrm{N}=\mathrm{H}$ in

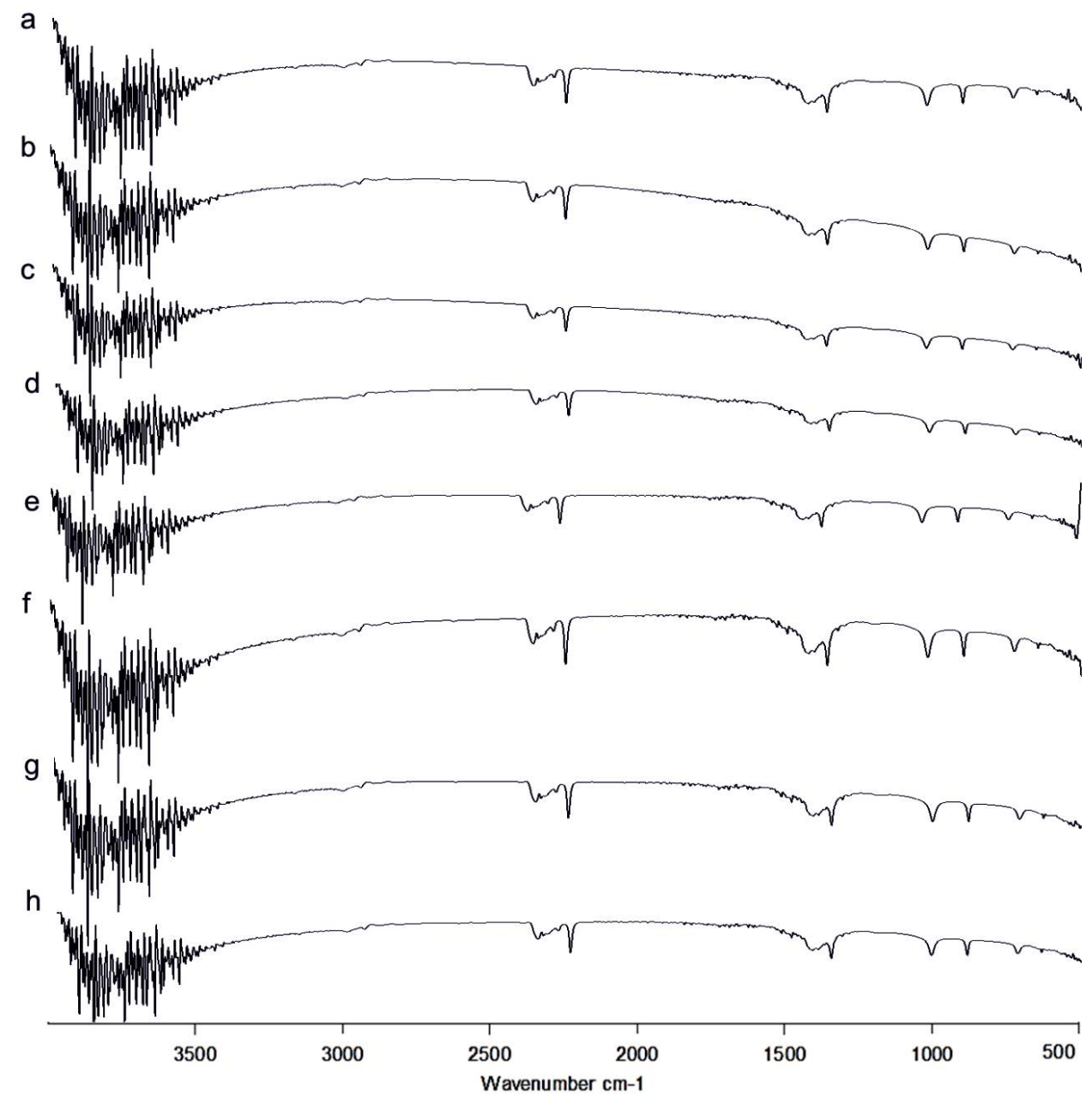

Fig. 4. FT-IR of Acyl Homoserine Lactone

a) Control, b) Punica granatum, c) Citrus reticulata, d) Vitis amurensis, e) Carica papaya, f) Vitis vinifera, g) Ananas comosus, h) Ficus carica 
the acyl chain ${ }^{32}$ (Figure 4a-h), and peak between $1,200-9,00 \mathrm{~cm}^{-1}$ was attributed to characteristic of C-O-C stretching, the peaks at $1718 \mathrm{~cm}^{-1}$ and $1038 \mathrm{~cm}^{-1}$ corresponds to $\mathrm{C}=\mathrm{O}$ of lactone ring and $\mathrm{N}-\mathrm{H}$ respectively ${ }^{33}$. Kushwaha et al. $^{34}$ have used LC-MS/MS technique for detecting the quorum sensing molecules and also studied the impact on the same by plant derivatives in $P$. aeruginosa, confirmed its sensitivity to biofilm forming. On evaluating the $M-S$ results in positive ion mode, the peaks recorded at $197.7 \mathrm{~m} / \mathrm{z}, 258 \mathrm{~m} / \mathrm{z}$ and 300 $\mathrm{m} / \mathrm{z}$ corresponds to C4-HSL (homoserine lactone), C10-HSL and 3-0-12HSL respectively ${ }^{35,36,37}$ (Fig. 7). Unfortunately, fruit extracts do not have direct impact on the functional group as well as in production of $\mathrm{AHL}$ from Pseudomonas aeruginosa $\mathrm{SU}-18$. The degradation of the signaling molecule30C12HSL in Pseudomonas aeruginosa was identified by the action of AHL acylase from a soil pseudomonad strain PAI-A. It was confirmed by Huang et al. $^{38}$ on monitoring the HSL- releasing activity by LC/APCI-MS technique.

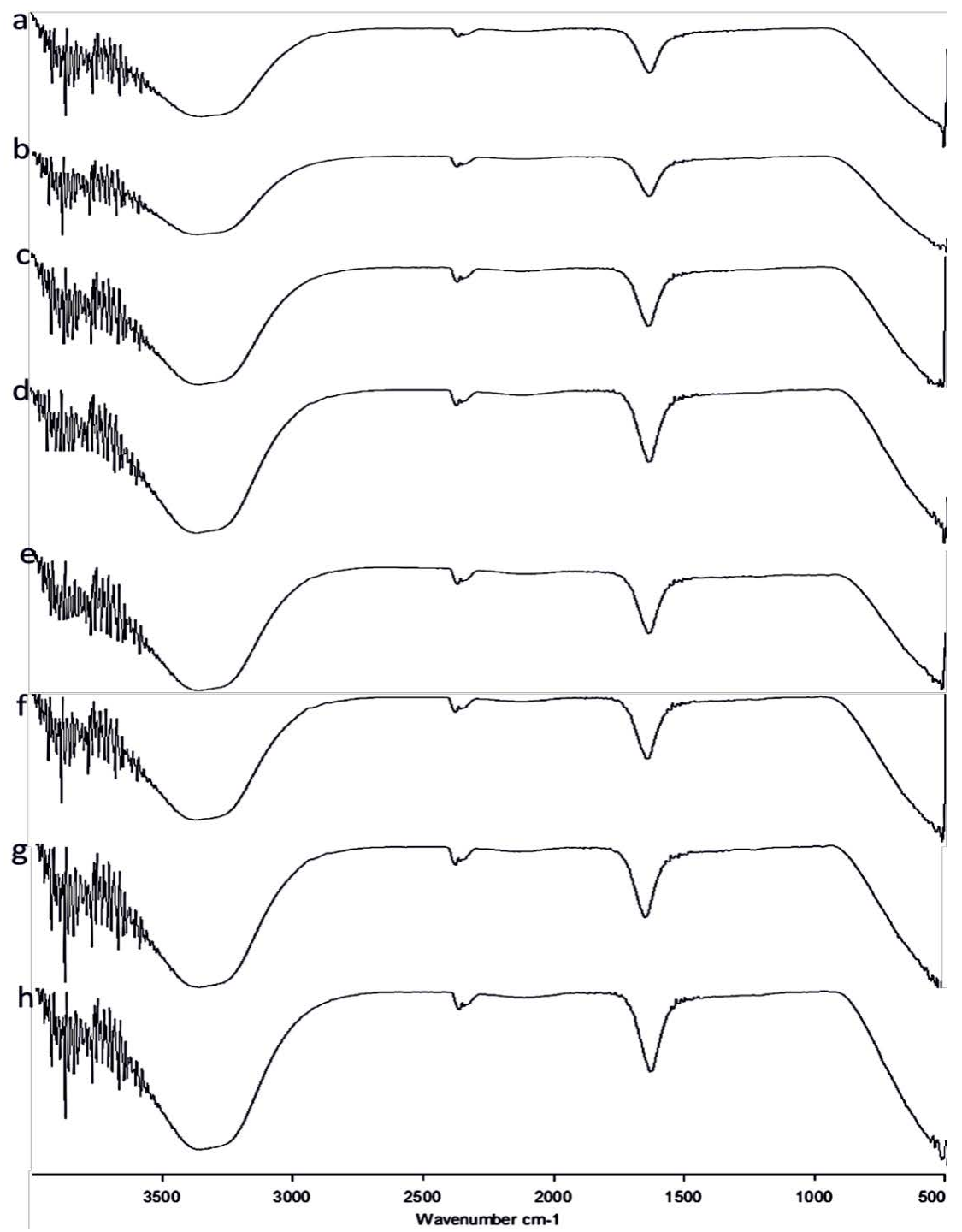

Fig. 5. FT-IR of Pyocyanin extracted

(a) Control, (b) Punica granatum, (c) Citrus reticulata, (d) Vitis amurensis, (e) Carica papaya, (f) Vitis vinifera, (g) Ananas comosus, (h) Ficus carica 


\section{Impact on pyocyanin pigment}

The Presence of peak at $1637.82 \mathrm{~cm}^{-1}$ in all the extracted samples as observed in(Fig. 5 $\mathrm{a}-\mathrm{h}$ ) corresponded to $\mathrm{C}=\mathrm{N}$ bond ${ }^{39}$. The band range between $3400-3300 \mathrm{~cm}^{-1}$ indicated the presence of $-\mathrm{OH}$ group in the extracted pyocyanin ${ }^{40}$. From the LC-MS analysis in positive ion mode (Fig 8ah), the peak at $211 \mathrm{~m} / \mathrm{z}$ represents pyocyanin ${ }^{41}$ and the presence of pyochelin was detected from the peak sensed at $338 \mathrm{~m} / \mathrm{z}^{42}$. Punica granatum showed impact on the synthesis of phenazine pyocyanin and Pyochelin production whereas only Pyochelin production was affected in the case of Citrus reticulata, Vitis amurensis and Vitis vinifera treated cultures (Fig. 8). Bacterial isolate from sponge were found to be effective against the pyocyanin production in P. aeruginosa $\mathrm{PAO}^{43}$.

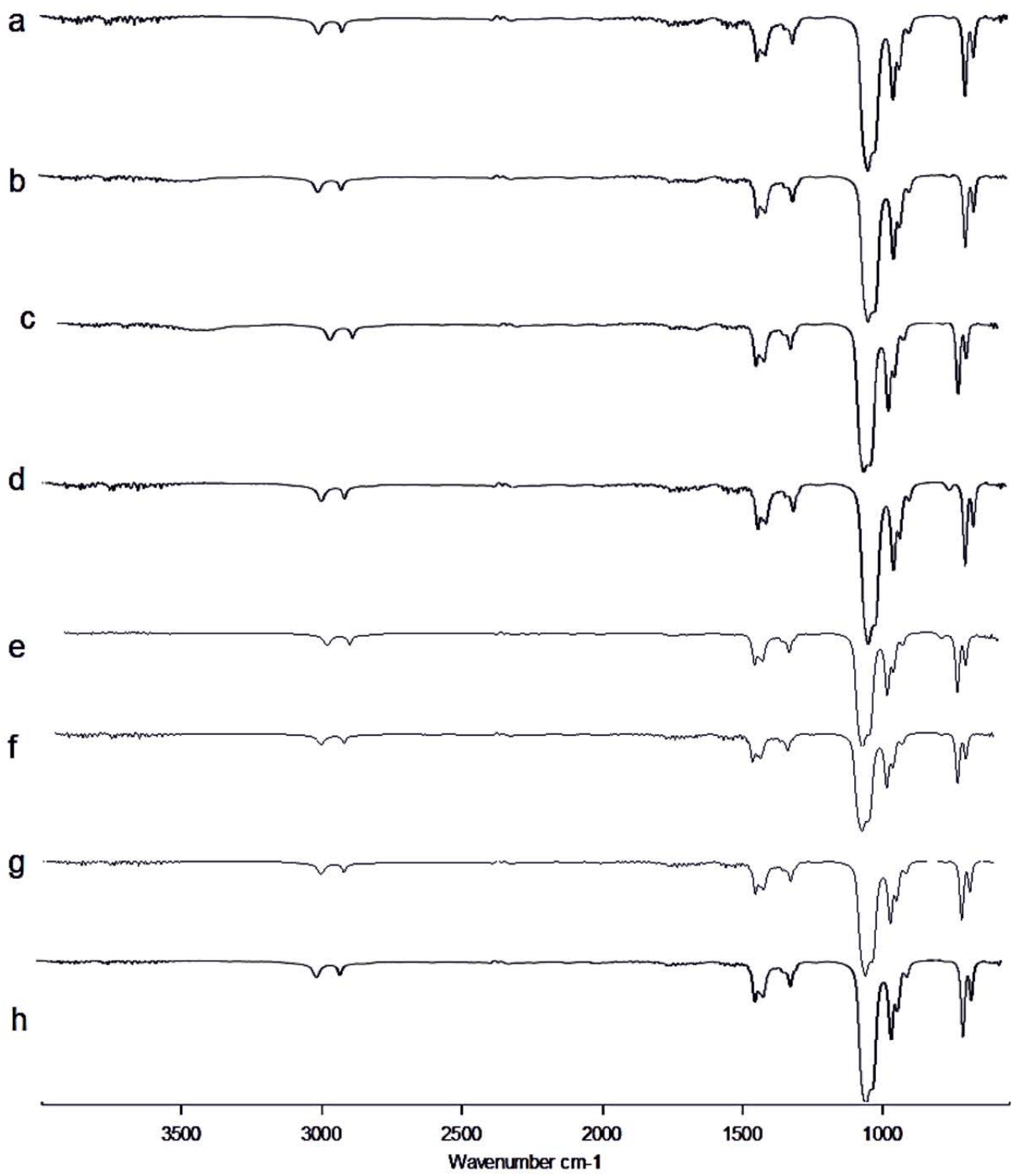

Fig. 6. FT-IR of Rhamnolipid extracted

(a) Control, (b) Punica granatum, (c) Citrus reticulata, (d) Vitis amurensis, (e) Carica papaya,

(f) Vitis vinifera, (g) Ananas comosus, (h) Ficus carica 


\section{Impact on Rhamnolipid}

FT-IR spectrum of Rhamnolipid showed distinct vibrations at the wave numbers $2994 \mathrm{~cm}^{-1}$ and $2912 \mathrm{~cm}^{-1}$ due to asymmetric $\mathrm{C}-\mathrm{H}$ stretching of $\mathrm{CH}_{2}$ and $\mathrm{CH}_{3}$ which is the aliphatic group, 1508 $\mathrm{cm}^{-1}$ was due to $\mathrm{C}=\mathrm{C}$ stretching. The deformation vibrations at $1435 \mathrm{~cm}^{-1}$ and $1309 \mathrm{~cm}^{-1}$ showed the presence of alkyl groups ${ }^{44}$ and $951 \mathrm{~cm}^{-1}$ corresponded to aromatic groups ${ }^{45}$ (Fig. 6 a-h). Vibration near $1064 \mathrm{~cm}^{-1}$ is for the glycosidic bond $(\mathrm{C}-\mathrm{O}-\mathrm{C})$ and methyl and methylene groups were confirmed by vibration near $2700-3000$ $\mathrm{cm}^{-146}$ (Fig. 6 a-h). No functional group shift was observed due to fruit juices. The negative ion mode were estimated from the result of LC-MS analysis for Rhamnolipid extracted from P.aeruginosa,

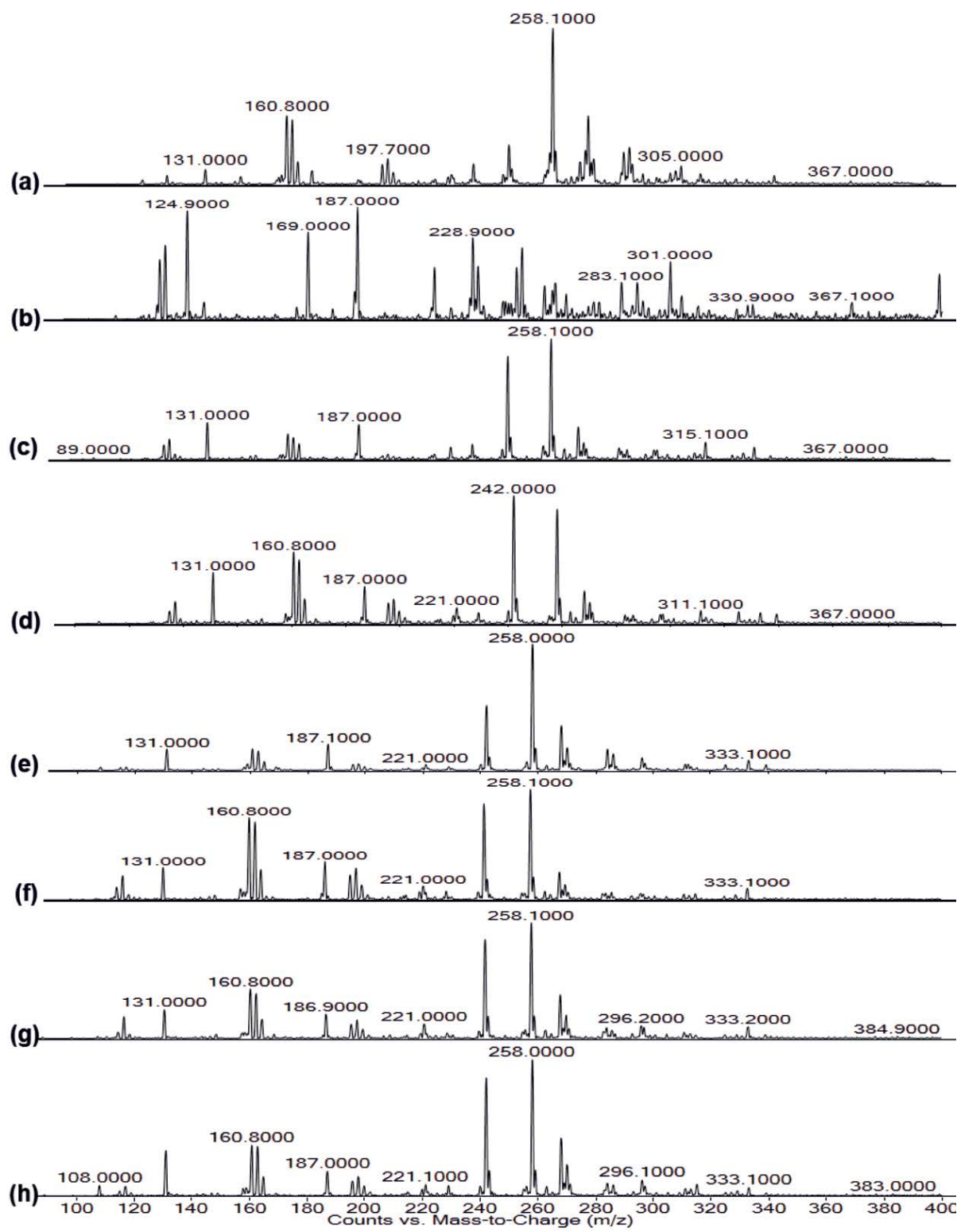

Fig. 7. LC-MS of AHL extracted

(a) Control, (b) Punica granatum, (c) Citrus reticulata, (d) Vitis amurensis, (e) Carica papaya,

(f) Vitis vinifera, (g) Ananas comosus, (h) Ficus carica 
the peaks obtained at $313 \mathrm{~m} / \mathrm{z}$ corresponds to Rha-C 8 and at $503 \mathrm{~m} / \mathrm{z}$ was due to the detection of Rha $\mathrm{C}^{4} 0^{46}$ (Fig 9a). Rha C10 was not sensed in the Rhamnolipid extracted from Citrus reticulata, Vitis amurensis, Vitis vinifera and Ficus carica treated P.aeruginosa (Fig. 9. c, d, f, h) thereby the impact of fruit molecules against biosurfactants was understood. Even Kushwaha et al. ${ }^{34}$ found capsaicin and 6-gingerol to have impact on rhamnolipid.

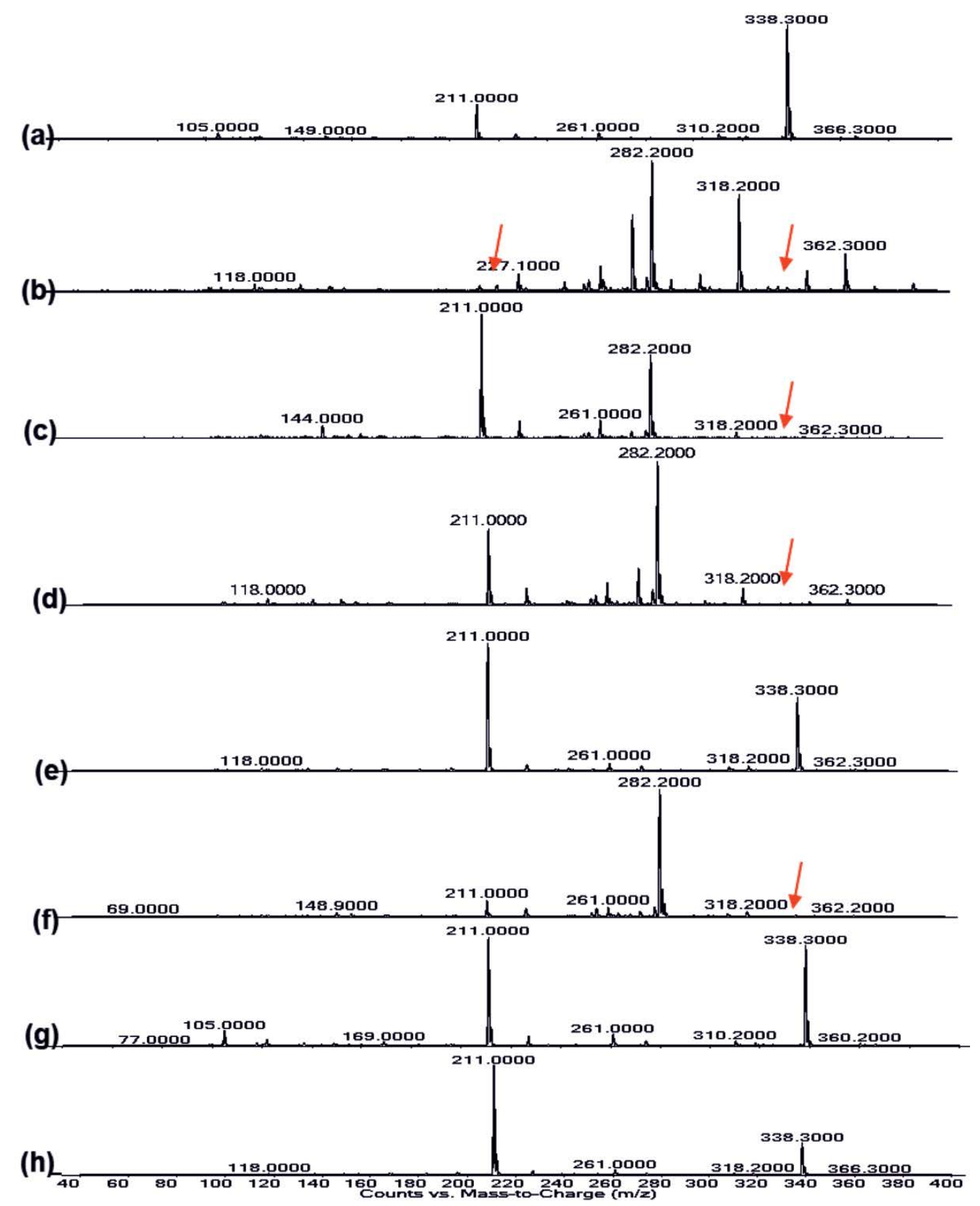

Fig. 8. LC-MS of pyocyanin extracted

(a) Control, (b) Punica granatum, (c) Citrus reticulata, (d) Vitis amurensis, (e) Carica papaya,

(f) Vitis vinifera, (g) Ananas comosus, (h) Ficus carica 


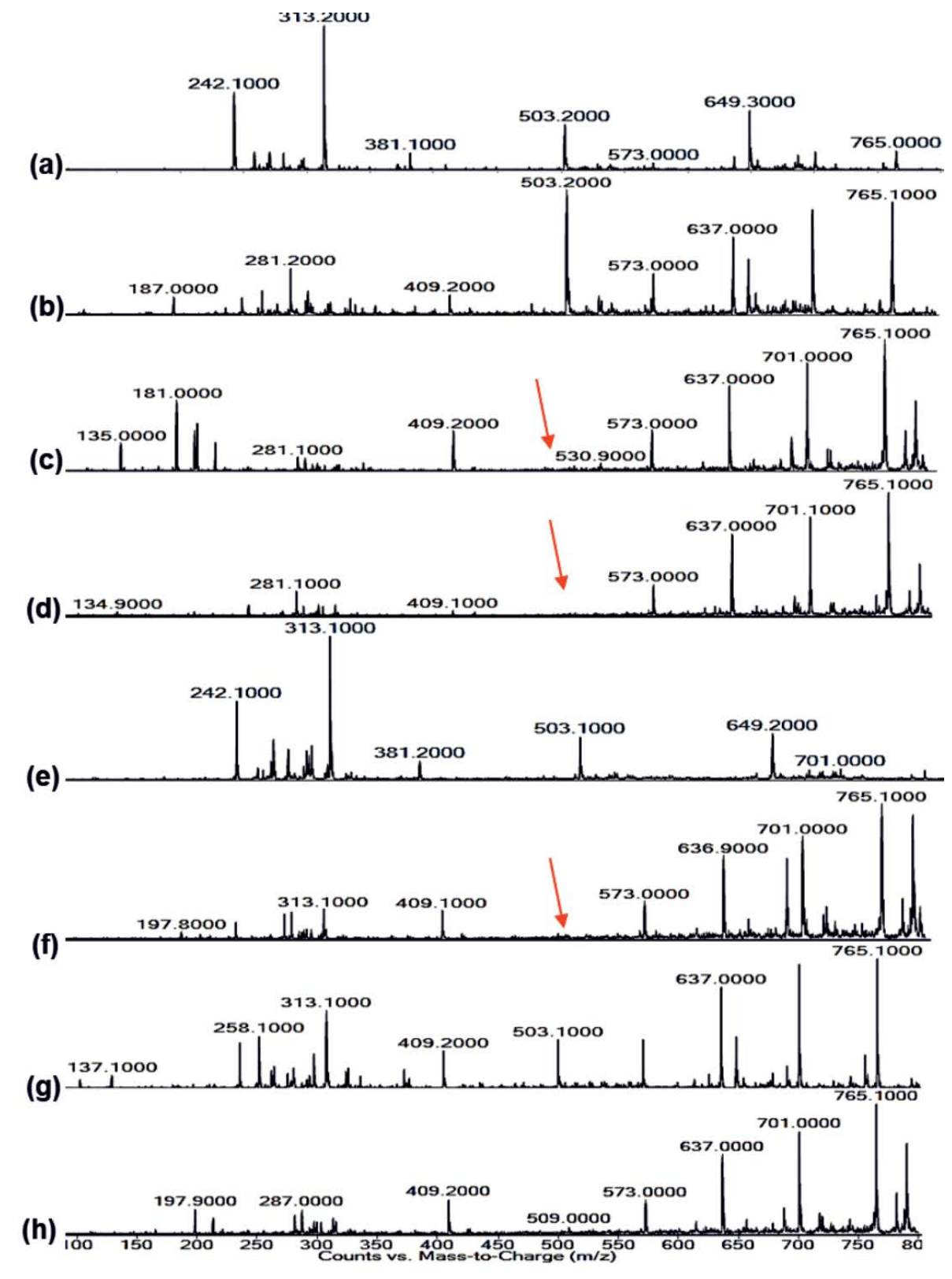

Fig. 9. LC-MS of Rhamnolipid extracted

(a) Control, (b) Punica granatum, (c) Citrus reticulata, (d) Vitis amurensis, (e) Carica papaya, (f) Vitis vinifera, (g) Ananas comosus, (h) Ficus carica

\section{CONCLUSION}

All the above used fruit juices possessed antioxidant property which was confirmed by TLC bioautography, DPPH \& FRAP assay. The presence of certain fatty acids and its derivates such as oleic acid, decenoic acid and phenols, quinolin compounds was found to show anti-biofilm action in various species, $P$. aeruginosa, E. coli, K. pneumoniae, Proteus mirabilis, Streptococcus pyogenes, B. subtilis, S. aureus ${ }^{47}$. Correspondingly, the presence of such components in fruit juices was confirmed by GC-MS analysis in our former report ${ }^{13}$.These anti-biofilm agents could possibly play a major role by interrupting the physiological 
synthesis of $\mathrm{AHL}$ and other virulence factors. The specific pigment namely Pyochelin production was greatly affected in Citrus reticulata, Vitis amurensis and Vitis vinifera treated cultures. Also, LC-MS analyser for RhamnolipidRha C10 further confirmed Citrus reticulata, Vitis amurensis, Vitis vinifera and Ficus carica treated P.aeruginosa are passive to biosurfactant production.

\section{ACKNOWLEDGMENTS}

None.

\section{CONFLICT OF INTEREST}

The authors declare that they have no conflict of interest.

\section{AUTHORS' CONTRIBUTION}

All the authors involved in idea creation and made intellectual contribution to the work. All the authors involved in manuscript preparation.

\section{FUNDING}

None.

\section{DATA AVAILABILITY}

All datasets generated or analyzed during this study are included in the manuscript.

\section{ETHICS STATEMENT}

Not applicable.

\section{REFERENCES}

1. Vital-Lopez, F.G., Reifman, J., Wallqvist, A. Biofilm Formation Mechanisms of Pseudomonas aeruginosa Predicted via Genome-Scale Kinetic Models of Bacterial Metabolism. PLoS Comput Biol., 2015; 11(10): e1004452. https://doi.org/10.1371/journal. pcbi.1004452

2. Rasamiravaka, T., Labtani, Q., Duez, P., Jaziri, M.E. The Formation of Biofilms by Pseudomonas aeruginosa: A Review of the Natural and Synthetic Compounds Interfering with Control Mechanisms. Bio Med. Research International, 2015. http://dx.doi. org/10.1155/2015/759348.

3. Charlton, T.S., De Nys, R., Netting, A., Kumar, N., Hentzer, M., Givskov, M., Kjelleberg, S. A novel and sensitive method for the quantification of N-3-oxo-acyl homoserine lactones using gas chromatography-mass spectrometry: application to a model bacterial biofilm. Environ. Microbiol., 2000; 2: 530-541. https://doi. org/10.1046/j.1462-2920.2000.00136.x

4. Antunes, L.C.M., Ferreira, R.B.R., Buckner, M.M.C., Finlay, B.B. Quorum sensing in bacterial virulence. Microbiology, 2010; 156: 2271-2282. doi: 10.1099/mic.0.038794-0 https://doi.org/10.1099/ mic.0.038794-0

5. Schuster, M., Greenberg, E.P. A network of networks: quorum-sensing gene regulation in Pseudomonas aeruginosa. Int. J. Med. Microbiol., 2006; 296(2-3): 73-81. https://doi.org/10.1016/j.ijmm.2006.01.036

6. Passador, L., Cook, J.M., Gambello, M.J., Rust, L., Iglewski, B.H. Expression of Pseudomonas aeruginosa virulence genes requires cell-to-cell communication. Science, 1993; 260(5111): 1127-30. https://doi. org/10.1126/science.8493556

7. Ochsner, U.A., Koch, A.K., Fiechter, A., Reiser, J. Isolation and characterization of a regulatory gene affecting rhamnolipid biosurfactant synthesis in Pseudomonas aeruginosa. J. Bacteriol., 1994; 176(7): 2044-54. https://doi.org/10.1128/jb.176.7.20442054.1994

8. Chang, C.Y. Surface Sensing for Biofilm Formation in Pseudomonas aeruginosa. Front Microbiol., 2017; 8: 2671. doi: 10.3389/fmicb.2017.02671. https://doi. org/10.3389/fmicb.2017.02671

9. Lu, L., Hu, W., Tian, Z., Yuan, D., Yi, G., Zhou, Y., Cheng, Q., Zhu, J., Li, M. Developing natural products as potential anti-biofilm agents. Chin. Med., 2019; 20(14): 11. doi: 10.1186/s13020-019-0232-2. https://doi. org/10.1186/s13020-019-0232-2

10. Chang, C.Y., Krishnan, T., Wang, H., Chen, Y., Yin, W.F., Chong, Y.M., Tan, L.Y., Chong, T.M., Chan, K.G. Nonantibiotic quorum sensing inhibitors acting against $\mathrm{N}$-acyl homoserine lactone synthase as druggable target. Scientific Reports, 2014; 4: (7245). https://doi. org/10.1038/srep07245

11. Chong, Y.M., How, K.Y., Yin, W.F., Chan, K.G. The Effects of Chinese Herbal Medicines on the Quorum SensingRegulated Virulence in Pseudomonas aeruginosa PAO1. Molecules., 2018; 23(4): 972. doi: 10.3390/ molecules23040972. https://doi.org/10.3390/ molecules23040972

12. Husain, F.M., Ahmad, I., Khan, M.S., Al-Shabib, N.A. Trigonella foenum-graceum (Seed) Extract Interferes with Quorum Sensing Regulated Traits and Biofilm Formation in the Strains of Pseudomonas aeruginosa and Aeromonas hydrophila. EvidenceBased Complementary and Alternative Medicine, 2015; https://doi.org/10.1155/2015/879540

13. Samrot, A.V., Raji, P., Selvarani, A.J., Nishanthini, P. Antibacterial activity of some edible fruits and its green synthesized silver nanoparticles against uropathogen - Pseudomonas aeruginosa SU 18, Biocatalysis and Agricultural Biotechnology, 2018; 16: 253-270.

14. Xiao, G., Li, G., Chen, L., Zhang, Z., Yin, J., Wu, T., Cheng, Z., Wei, X., Wang, Z. Isolation of antioxidants from Psoralea coryliffolia fruits using high-speed counter-current chromatography guided by thin layer chromatography-antioxidant autographic assay, J. Chromatogr A., 2010; 1217: 5470-5476. https://doi. org/10.1016/j.chroma.2010.06.041

15. Rahman, M.M., Islam, M.B., Biswas, M., Khurshid Alam, A.H. In vitro antioxidant and free radical scavenging activity of different parts of Tabebuia pallida growing in Bangladesh. BMC research notes., 2015; 8: 621. https://doi.org/10.1186/s13104-015-1618-6 
16. Loganayaki, N., Siddhuraju, P., Manian, S. Antioxidant activity and free radical scavenging capacity of phenolic extracts from Helicteres isora L. and Ceiba pentandra L. J. Food Sci. Technol., 2013; 50(4): 687-95. https://doi.org/10.1007/s13197-011-0389-x

17. Singh, H.P., Kaur, S., Negi, K., Kumari, S., Saini, V., Batish, D.R., Kohli, R.K. Assessment of in vitro antioxidant activity of essential oil of Eucalyptus citriodora (lemon-scented Eucalypt; Myrtaceae) and its major constituents, LWT- Food Science and Technology, 2012; 48(2): 237-241 https://doi.org/10.1016/j. Iwt.2012.03.019

18. Chen, F., Gao, Y., Chen, X., Yu, Z., Li, X. Quorum Quenching Enzymes and Their Application in Degrading Signal Molecules to Block Quorum Sensing-Dependent Infection. Int. J. Mol. Sci., 2013; 14(9): 17477-17500. https://doi.org/10.3390/ijms140917477

19. Essar, D.W, Eberly, L., Hadero, A., Crawford, I.P. Identification and characterization of genes for a second anthranilate synthase in Pseudomonas aeruginosa: interchangeability of the two anthranilate synthases and evolutionary implications. J. Bacteriol., 1990; 172(2): 884-900. https://doi.org/10.1128/ jb.172.2.884-900.1990

20. Narendrakumar, G., Saikrishna, N.M.D., Prakash, P., Preethi, T.V. Production, characterization, and optimization of rhamnolipids produced by Pseudomonas aeruginosa by solid-state fermentation. International Journal of Green Pharmacy., 2017; 11(2): 93.

21. George, S., Jayachandran, K. Production and characterization of rhamnolipid biosurfactant from waste frying coconut oil using a novel Pseudomonas aeruginosa D. J. Appl. Microbiol., 2013; 114(2): 373-83. https://doi.org/10.1111/jam.12069

22. Rajan, S., Mahalakshmi, S., Deepa, V.M., Sathya, K., Shajitha, S., Thirunalasundari, T. Antioxidant Potentials of Punica Granatum Fruit Rind Extracts. Int. J. Pharm. Pharm. Sci., 2011; 3(3): 8288.

23. Basiri, S. Evaluation of antioxidant and antiradical properties of Pomegranate (Punica granatum L.) seed and defatted seed extracts. J. Food Sci. Technol., 2015; 52(2): 1117-1123. https://doi.org/10.1007/s13197013-1102-z

24. Haripyaree, A., Guneshwor, K., Damayanti, M. Evaluation of Antioxidant Properties of Phenolics Extracted from Ananas comosus L. Not. Sci. Bio., 2010; 2(2): 68. https://doi.org/10.15835/nsb224615

25. Yi, Z.B., Yu, Y., Lian, Y.Z.,Zeng, B. In vitro antioxidant and antimicrobial activities of the extract of Pericarpium Citri Reticulatae of a new Citrus cultivar and its main flavonoids. LWT-Food Science and Technology, 2008; 41: 597-603. https://doi.org/10.1016/j. Iwt.2007.04.008

26. Annegowda, H.V., Bhat, R., Yeong, K.J., Liong, M.T., Karim, A.A., Mansor, S.M. Influence of drying treatments on polyphenolic contents and antioxidant properties of raw and ripe papaya (Carica papaya L.). International Journal of Food Properties, 2013; 17: 283-292. https://doi.org/10.1080/10942912.2011.6 31248

27. Junior, M.R.M., Silva, T.A.A.R.e, Franchi, G.C.,
Nowill, A., Pastore, G.M., Hyslop, S. Antioxidant potential of aroma compounds obtained by limonene biotransformation of orange essential oil. Food Chemistry, 2009; 116(1): 8-12. https://doi. org/10.1016/j.foodchem.2009.01.084

28. Misharina, T.A., Samusenko, A.L. Antioxidant properties of essential oils from lemon, grapefruit, coriander, clove and their mixtures. Applied Biochemistry and Microbiology, 2008; 44: 482-486. https://doi. org/10.1134/S0003683808040182

29. Hassimoto, N.M., Genovese, M.I., Lajolo, F.M. (2005). Antioxidant activity of dietary fruits, vegetables, and commercial frozen fruit pulps. Journal of Agricultural and Food Chemistry, 2005; 53: 2928-2935. https://doi. org/10.1021/jf047894h

30. Kongsuwan, A., Suthiluk, P., Theppakorn, T., Srilaong, V., Setha, S. Bioactivecompounds and antioxidant capacities of Phulae and nanglae pineapple. Asian Journal of Food and Agro-Industry, 2009; 2: 44-50.

31. Ali, B., Mujeeb, M., Aeri, V., Mir, S.R., Faiyazuddin, M.,Shakeel, F. Anti-inflammatory and antioxidant activity of Ficus carica Linn. leaves. Natural Product Research, 2012; 26: 460-465. https://doi.org/10.108 $0 / 14786419.2010 .488236$

32. Taghadosi, R., Shakibaie, M.R., Masoumi, S. Biochemical detection of N-Acyl homoserine lactone from biofilmforming uropathogenic Escherichia coli isolated from urinary tract infection samples. Rep. Biochem. Mol. Biol., 2015; 3(2): 56-61.

33. Prasad, P.K., Sharma, P., Shlini, P. Isolation and Characterization of Biofilm Forming Bacteria from Urinary Tract Infected Patients. IJPSR, 2018; 9(5): 1886-1894.

34. Kushwaha, M., Jain, S.K., Sharma, N., Abrol, V., Jaglan, S., Vishwakarma, R.A. Establishment of LCMS Based Platform for Discovery of Quorum Sensing Inhibitors: Signal Detection in Pseudomonas aeruginosa PAO1. ACS Chem. Biol., 2018; 13(3): 657-665. https://doi. org/10.1021/acschembio.7b00875

35. Khan, S., Mumtaz, A.S., Mustafa, G., Naveed, M., Shinwari, Z.K., Downie, A. The LC-MS/MS Profiling of AHLs Produced in Sinorhizobium Meliloti nodulating Alysicarpus Bupleurifolius. Pak. J. Bot., 2013, 45(6): 2037- 2041.

36. Ransome, E., Munn, C.B., Halliday, N., Camara, M., Tait, K. Diverse profiles of $\mathrm{N}$-acyl-homoserine lactone molecules found in cnidarians. FEMS Microbiol. Ecol., 2014; 87: 315-329. https://doi.org/10.1111/15746941.12226

37. Samrot, A.V., Azeemullah, S.A., Sujitha, R., Azharudeen, S.M., Samanvitha, S.K., Sneha, S.J.Characterization of Acyl Homoserine Lactone of pigment producing Pseudomonas aeruginosa SU-3. Der Pharma Chemica., 2016; 8(9): 74-79.

38. Huang, J.J., Han, J.I., Zhang, L.H., Leadbetter, J.R. Utilization of acyl-homoserine lactone quorum signals for growth by a soil pseudomonad and Pseudomonas aeruginosa PAO1. Appl. Environ. Microbiol., 2003; 69(10): 5941-5949. https://doi. org/10.1128/AEM.69.10.5941-5949.2003

39. Laxmi, M., Bhat, S.G.Characterisation of pyocyanin with radical scavenging and antibiofilm properties 
isolated from Pseudomonas aeruginosa strain BTRY1, Springer, 2016; 6(27): 1-5. https://doi.org/10.1007/ s13205-015-0350-1

40. Devnath, P., Uddin, M.K., Ahamed, F., Hossain, M.T., Manchur, M.A. Extraction, purification and characterization of pyocyanin produced by Pseudomonas aeruginosa and evaluation for its antimicrobial activity. Int. Res. J. Biological Sci., 2017; 6(5): 1-7.

41. Leipert, J., Bobis, I., Schubert, S., Fickenscher, H., Leippe, M., Tholey, A. Miniaturized dispersive liquidliquid microextraction and MALDI MS using ionic liquid matrices for the detection of bacterial communication molecules and virulence factors. Anal. Bioanal. Chem., 2018; 410(19): 4737-4748. https://doi.org/10.1007/ s13205-015-0350-1

42. Phelan, V.V., Fang, J., Dorrestein, P.C. Mass Spectrometry Analysis of Pseudomonas aeruginosa Treated with Azithromycin. J. Am. Soc. Mass Spectrom., 2015; 26: 873-877. https://doi.org/10.1007/s13361-015-1101-6

43. Saurav, K., Bar-Shalom, R., Haber, M., Burgsdorf, I., Oliviero, G., Costantino, V., Morgenstern, D., Steindler, L. In Search of Alternative Antibiotic Drugs: Quorum-
Quenching Activity in Sponges and their Bacterial Isolates. Front. Microbiol., 2016; 5(7): 416. https:// doi.org/10.3389/fmicb.2016.00416

44. Vijaykumar, S., Saravanan, V. In Vitro cytotoxicity and antimicrobial activity of biosurfactant produced by Pseudomonas aeruginosa strain PB3A. Asian Journal of Scientific Research, 2015; 8: 510-518. https://doi. org/10.3923/ajsr.2015.510.518

45. Narayanan, J., Ramji, R., Sahu, H., Gautam, P.Synthesis, stabilization and characterization of rhamnolipidcapped $\mathrm{ZnS}$ nanoparticles in aqueous medium. IET Nanotechnol., 2011; 4: 29-34. https://doi. org/10.1049/iet-nbt.2009.0010

46. Arutchelvi, J., Doble, M. Characterization of glycolipid biosurfactant from Psuedomonas-aeruginosa $\mathrm{CPCL}$ isolated from petroleum-contaminated soil, Lett. Appl Microbiol., 2010; 51(1): 75-82. https://doi. org/10.1111/j.1472-765X.2010.02858.x

47. Rabin, N., Zheng, Y., Opoku-Temeng, C., Du, Y., Bonsu, E., O Sintim, H. Agents that inhibit bacterial biofilm formation. Future Medicinal Chemistry, 2015; 7. https://doi.org/10.4155/fmc.15.7 